\title{
Developing a Mobile Learning Maturity Model
}

\author{
Muasaad Alrasheedi, Luiz Fernando Capretz \\ University of Western Ontario, Canada
}

\begin{abstract}
Addition of features such as internet access via wireless and other sophisticated functions have converted the present day mobile phone into smart devices with multiple applications. One such area is the educational sector, where several features of mobile phone come in handy. Mobile Learning or $\mathrm{m}^{-}$ Learning is increasingly gaining importance among learners, educators, and institutions as a medium of education. In view of the ubiquitous nature of mobile technology and the immense opportunities it offers, there are favorable indications that the technology could be introduced as the next generation of learning platforms. M-learning platform however lacks a comprehensive assessment and evaluation methodology, which is hampers its implementation considering the rapidly changing technology. In this context this paper addresses the question: "Can the notion of the capability maturity model (CMM) be adapted to propose m-Learning maturity?". The basic idea is to consider and use the CMM framework as an inspiration to build a model appropriate for m-Learning that would help measure the maturity of educational institutions in adopting m-Learning. This is a preliminary discussion based on the current understanding of the issue.
\end{abstract}

\section{Introduction}

Present day mobile phones are powerful smart devices with several sophisticated features prompting a wide array of possible applications. One such application is the use of phone phones to modify and enhance the learning process. Mobile assisted learning can work as a stand-alone learning platform or seamless attach with other learning platforms to form a blended learning platform. The development of a mobile learning paradigm has become the focus of several studies and researches. The topic has been especially explored in-depth in the research studies of Kukulska-Hulme et al. [1] and Engel et al. [2]. The idea of learning using mobile phones is however not limited to the university context, and has been explored in detail in several other learning contexts such as on-the-job training and professional learning activities within organizations. In fact m-Learning has been more readily welcomed and experiments more of a success in professional working environments. Mobile learning offers the advantage of maximizing the number of students and at the same time reducing the overall cost of institutional processes [3] [4]. The results of various studies conducted on mobile learning with the university context almost universally agree on the existence of several challenges that impact m-Learning adoption in the institutional context. Because of the multiple adoption challenges, not to mention the high initial financial requirements for setting up the platform up and running, has led to very few universities actually adopting the platform as an alternate learning paradigm or even in the blended learning context. The universities that have actually adopted the platform however agree upon the multiple benefits of the systems [5]. One of the key challenges in the adoption of m-Learning is aptly pointed out by Wishart \& Green [6]. According to these researchers there is a lack of comprehensive evaluation of the complete m-Learning platforms, especially in higher education. The assessments have usually been superficial and not of much help when their results are viewed from the perspective of improving the existing platform. Another challenge in the adoption of m-Learning in high education institutions is the identification of the ideal strategic priorities and process for making it easy to invest in the industry of m-Learning, especially to cope with the quickly changing environment of technology [3].

We attempt to address this crucial gap by developing efficient assessment mechanisms which could be employed in order to evaluate the involved institution, especially in the terms of m-Learning adoption and implementations. In this context our idea is to develop a maturity model modeled on the CMM. Hence, the present paper address the first step of our efforts in this direction - How can we apply the CMM framework in the process of m-Learning in order to provide better assessment and evaluation for higher educational institutions?

It is a fact that the educational requirements of the students are highly subordinate to the requirements of technical teaching. However, it appears to be difficult for the involved educators to facilitate the process of learning and for the teachers to acquire hands-on experience on the platform [2]. Generally speaking both e-learning and m-Learning can offer valuable models of learning, which can be used by teachers in universities interested in adopting $\mathrm{m}$ Learning platforms so that they can have ongoing access to the available informational resources and employ these modules with care.

M-Learning, in a way is a subtype, of e-learning where sophisticated personal digital assistants are employed to bring necessary information to the fingertips of the learners, with or without accessing the internet. Needless to say such technologies are 
both complex and comprehensive and can target either or both learning enhancement and knowledge delivery, simply to build skills and knowledge [7].

This can be particularly seen as promising however, when such technological advancements can utilize both contents and methods of multi-media instructions. Therefore, it is important to notice that $\mathrm{m}$-Learning can allow the involved students to access the required information according to their corresponded schedules. Moreover, it can provide additional chances to revise the needed materials [8].

In recent times, several education experts have started addressing the attitudes towards new educational technologies. Several studies have also shown that the process of learning based techniques, such as e-learning, m-Learning, and other advanced methods, could be equal to the traditional lecture format [7]. It is important that the framework used to assess any software application platform, including m-Learning, should not confine itself to technical and design aspects but must also include metrics determining ease of adoption and usage for users [9].

To determine the specific attitudes and other tangible requirements for success adopting mLearning, it is important to have an overall assessment framework. A maturity framework would help in improving the process involved and ensure sustainability in enhancing the outcomes of students learning. The rapid growth of mobile technology and its increasing application in different areas means that its entry into the educational sector is inevitable, sooner rather than later. Hence, developing a robust assessment framework for adoption of m-Learning is a worthwhile exercise. Capability Maturity Model (CMM) has been a proven success in adoption of software platforms across several different areas that were used to a more traditional approach to work. Hence, it is reasonable to assume that some form of CMM-type model would be the most efficient and effective framework [10].

This paper is structured as follows: Section 2 discusses the research motivations and goals. Section 3 provides the relevant background literature review on mobile learning. Related research work is presented in Section 4. Section 5 provides an analysis and discussion on proposed model. Finally, the conclusion is stated in section 6 .

\section{Motivations and goals}

This paper attempts to answer the main question: Can the notion of the capability maturity model (CMM) be adapted to propose m-Learning maturity?

The basic goal of the present research is develop the outline for a maturity model for m-Learning. Moreover our aim is also to illustrate the various domains and stages in this maturity model, in order to assist the process of assessing m-Learning's performance at different stages of adoption.

Mobile phone was merely a fad a decade back and the access the limited to the developed nations of the world. In fact less than $70 \%$ of the world population had access to a cell phone in 2004 [11]. The situation has changed drastically in the last ten years. The use of mobile phone as spread rapidly and their popularity has grown phenomenally. The latest research by World Bank in 2012 shows that over three-quarters of the world population has access to the technology [12]. The statistics do not merely demonstrate the success of the technology but also the usability and flexibility of the mobile based technology. This is because the rapid spread of the technology extends to the versatility of its usage [13]. It is a commonly known fact that the mobile devices are multifunctional offering capable of high processing speeds and with large capacities of data storage. This combined with their compact nature and inherent mobility extends their application in several areas, including for learning purposes. The advantages that these versatile devices in the education sector is that they allow students to access their course materials as well as interact with fellow students and their instructors regardless of their location or the time. In other words, mobile technologies have the capability to support anytime/anywhere learning [14].

The immense advantages offered by m-Learning have not gone unnoticed as is evident from the fact that the global market for products related to $\mathrm{m}$ Learning reached $\$ 3.2$ billion in 2010. With researchers estimating the compound annual growth rate (CAGR) at $22.7 \%$ for the near future, it is clear that the m-Learning platform has arrived [15]. As a result, educational institutions are expected to include mobile learning as a core part of their learning platform to stay a part of the growing trend. Thus, there is an immense impetus to ensure successful implementation of a mobile platform within universities. In order to assess whether the mLearning has been successfully adopted by an educational institution it is important to develop an assessment framework. Only by employing the right evaluation framework would researchers and $\mathrm{m}$ learning stakeholders would be able to get a true picture of the current status of m-Learning implementation within the educational institution but also a roadmap for success that includes evaluation of m-Learning at important milestones. This is the objective of the present research.

\section{Literature review}

\subsection{Evolution of $m$-Learning}

Initially, in being involved with the process of $\mathrm{m}$ Learning, one should admit the basic elements of 
such a process, such as the teacher, the learner, the surrounding environment as well as the contents and, finally, assessment. Therefore, to simplify the matter, the following Fig. 1 shows such an easy involvement.

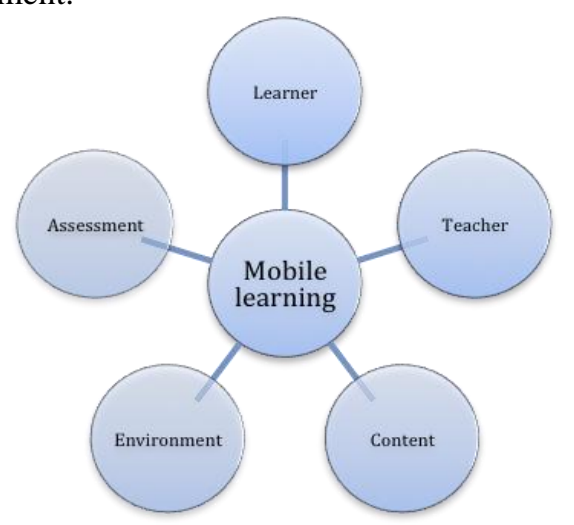

Adapted from: Ozdamli and Cavus bas [8] Figure 1. Basic elements of the m-Learning

Mobile technologies have already demonstrated in many countries that one can get benefits from using such devices in the education process [8]. m-Learning development offers endless valuable opportunities to both students and learners, considering the emergence of the highest technology of both networks and mobile devices [2]. Hence, we can assert that mobile technologies, especially after many continued years of evolving and development, have become so mature, simply to support the process of learning. The involved advanced devices of mobiles, for example, PDAs, iPod, wireless network and mobile phones techniques, might assist in making the $\mathrm{m}$-Learning process more feasible, especially in teaching and learning [8]. Moreover, there is a new attitude among the educational experts and institutions for adopting m-Learning, simply as such instructional strategies. Hence, one can forecast such alternative modes related to m-Learning concerning the involved learners' education, whereas such techniques allow more flexibility of the process of learning [1].

The matter became easy to employ such technique successfully, whereas the usage of m-Learning could verify the possibility of catching up with such ever changing world and moreover, to also boost collaboration and interaction among teachers and students [8].

Figuring out the starting ages of students for employing mobile techniques could indicate that new generations could already be adapted to this technology, simply to use mobile techniques in supporting the learning in classrooms. Such new generations are living in an environment that is full of mobile technologies [2]. Therefore, when one could use the mobile techniques regularly, the highest quality would be expected, simply in order to be boosted up later. m-Learning, consequently, would be our learning future that logically could expand the process of E-learning and, additionally, could have such potential to further expansion that, in turn, can make the process of learning available for all [3].

On the other hand, while developing the process of m-Learning, one should consider the new mode of learning with care, particularly when implementing it as a new educational option for learners. The matter requires balance, especially with the needs of students and, as well with such rapid technical development [4].

\subsection{Advantages of $m$-Learning}

Indeed, m-Learning involves many advantages, such as making the learning process easy at any time and at any place. This can save times and efforts of teachers, whereas the process of education can be involved with fun. In order for the m-Learning be successful and to obtain the highest benefits and advantages from it, one should consider the correspondent characteristics of such a valuable process [8].

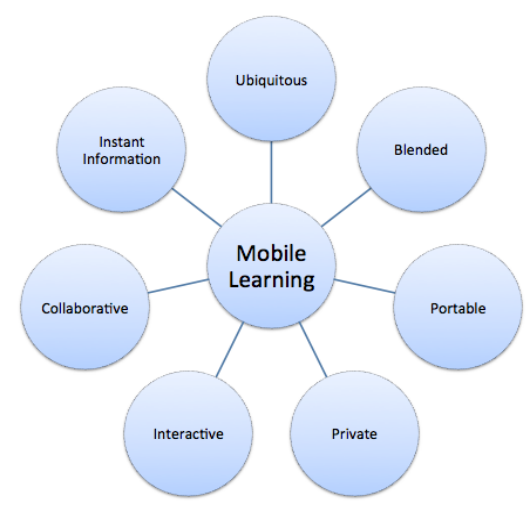

Adapted from: Ozdamli and Cavus [8]

Figure 2. The characteristics of $m$-Learning

Figure. 2 shows the characteristics of m-Learning; Ozdamli and Cavus [8] specified many characteristics of m-Learning, such as (i) ubiquitous/ spontaneous, (ii) the tools of the mobiles' portable size, (iii) private, (iv) blended, (v) collaborative and interactive, and (vi) instant information.

\subsection{Disadvantages of m-Learning}

Besides several advantages of m-Learning, one should consider the involved disadvantages of using m-Learning. Indeed, there are the set up costs for the involved equipment acquisition and, additionally, such training costs in the educational organization [16]. Moreover, the facts of copyright and security issues have recently become the main concern of the involved institutions; this may, indeed, expose such 
valuable data to unauthorized individuals, if the mobile technologies used appear insecure or even unsafe [17].

However, the matter still requires admitting that m-Learning is a creative and valuable means by which one can enhance the experience of learning, either at the workplace or in education [1] [17].

\subsection{Difference between e-Learning and m-Learning}

Initially, it is easy to notice that the existing difference between m-Learning and E-Learning can be found in the differing capabilities of the web browsers involved in each environment. However, it may be tempting to see E-Learning as an alternative to campus or classroom learning; therefore, mLearning can take such learning away, especially from certain fixed point. Whereas E-Learning is considered an alternative to learning in classrooms, m-Learning can be a complementary activity, especially to both traditional learning and ELearning. Most importantly, m-Learning considers the fact that the user involved will interact with many educational resources, while the students are apart from the normal place of education, the computer or even the classroom [7] [18] [19].

E-Learning has, indeed, been around for many more years than m-Learning, particularly with many types of the recent employment of m-Learning. Critically, m-Learning has been winning great approval, especially among young students who have grown up employing their portable videogames as well as their highest wireless technological devices. Corresponding to such meaning, m-Learning can appeal, not only to the persons who actually require portable, learning, but also to others who would like to use their mobile devices in either learning or playing games [7] [19].

\subsection{Factors influencing mobile learning in education}

A host of varied factors inspire learners and educators to make use of mobile application for learning purposes. Bidin and Ziden [20] have classified these motivational influences into three categories - device features, user expectations and advantages in pedagogy. A brief discussion of these factors is presented here.

I. Device features - This refers to the overall usage features of the mobile phone device and is further classified into two aspects: a. Device usability - One of the chief advantages of mobiles phones is its extreme portability, more than even a laptop. This in turn means that the mobile phone device retains all features of a basic handheld device such as being compact and lightweight

b. Device functionality - From the aspect of mobile learning, users require specific function features that are non-negotiable such as the ability to provide instant information, continuous connectivity, and responsiveness. Conventional mobile phones definitely have all these features but their importance increases considerably when they are observed from an m-Learning viewpoint

II. User expectations - This refers to the device expectations from a usage point. Following six aspects are a part of this:

a. Ownership - E-learning systems seem to work effectively in community setting, e.g. a shared e-learning center. In contrast, researches have shown that m-Learning systems would work best when they are owned by the users or at least when the users treat the device as their own [21]

b. Privacy - The mobile phone users also expect the device to offer a sense of privacy which they do not seem to expect from a laptop or PC. This is directly related to anytime-anywhere learning aspect.

c. Controlling learning - The features of $\mathrm{m}$-learning are not limited to mobility, they also refer to the measure of control extended by the learner over his/her learning process. This truly makes the device versatile.

d. Flexible learning - A direct extension of the user-controlled learning feature is the flexible learning aspect. Unlike traditional learning, mobile learning is not fixed to a time and place. The only technical requirement is the type of device and network connectivity.

e. Lifelong learning - Mobile learning platform allows learning to be an ongoing activity taking rather than being limited to a fixed degree duration.

f. Fun - Games are an integral part of a mobile phone and several researchers have argued in favor of them. It is often felt that educational games would teach concepts to learner better than standard 
rote learning or even practical learning schemes [22].

III. Advantages in Pedagogy - Mobile devices are considered to have some unique features that support teaching and learning. These factors are discussed below:

a. Collaboration opportunities - Learning has traditionally been seen as a solo activity primarily because one cannot be in touch with other learners all the time. The use of mobile offers this advantage, which makes it a unique system of learning and is seen to be singularly beneficial.

b. Blended learning - Researchers have always advocated that the best use of mobile phones in learning would be when it is combined with traditional learning giving the learners and educators the best of both worlds.

c. Interactive learning - Close on heels to the use of collaboration in learning, comes interaction. The interaction in this context means that users can learn by engaging with the technology such as find answers to their specific queries as and when they arise.

d. Contextual learning - Learning and application have always been seen as two separate activities. Mobile learning allows learners to apply-as-they-learn and learn-as-they-apply.

e. Problem-based learning - An example of such learning is the Norway based KNOWMOBILE project where smart mobile devices are used by medical students to discover and work with content that they deem is necessary to solve the current problem [23].

\subsection{Issues and challenges in Mobile Learning Applications}

Mobile learning offers immense advantages. However, the adoption of this platform has been very slow owing to the multiple application challenges. Bidin and Ziden [20] have conduct an in-depth analysis of the challenges and issues in mobile learning and classified them into two - challenges due to device and challenges due to user expectations. Both are discussed here:

I. Challenges due to mobile phone features:

a. Usability - While compact size is usually seen as an advantage, it also translates into small screen size as well as cumbersome mode for text input. Both these factors pose ergonomic challenges when users are expected to spend long hours learning using the device. Another issue with mobile phone is the lack of a consistent design scheme. Mobile phone come in several size and shapes, which makes it extremely difficult to develop a software application platform that would suit all mobile types.

b. Technical - In addition to the issues discussed above, mobile device users also have to face several technical challenges such as seamless network connectivity and intuitive hardware and software integration. Both these are taken for granted in laptops and PCs but the non-standard and roaming format of mobile phones makes it challenging to achieve the desired technical performance.

II. Challenges due to user expectations

a. Cost - Mobile phones cost less than computers, in general. However, the type of smart phone features required to maintain a good m-Learning application performance means purchasing expensive device that are usually beyond the budget of a large section of students.

b. Blockage - Social media applications are always a craze for school and college level students. At the same time school and university policies are strictly against their usage while studying. A firewall is possible for oncampus systems, but checking the behavior of students is not possible when they are in remote areas.

c. Obsolescence - One of the chief worries of most of the institutional management is that the rapid rate of obsolescence of the technology means that it would be difficult to recover the cost of the current infrastructure before an upgrade becomes necessary due to performance or security reasons.

\subsection{Capability maturity models (CMM)}

The use of the Capability Maturity Model or CMM was originally to assess the maturity of government contractors to work on a contracted software project [10]. CMM is basically a hierarchical model with five levels that helps to judge the maturity of various software contractors who are hired by the institutions or organizations to develop software applications. In addition, the framework also helps to identify critical steps and other validated practices that are required for the 
effective implementation of a process. Five levels of such model can be figured out as the following [10]:

1) Initial: in this case the developed process can be characterized as ad-hoc, whereas little processes can be defined and the resulting success may focus basically on the persons' heroics and efforts.

2) Repeatable: the process of the main project management is to be established to a certain track schedule, cost, as well as functionality. The process discipline needed can be seen in its place, in order to repeat the earlier success on such projects, especially with same application.

3) Defined: the development and management activities can be standardized, documented, and integrated into a set of friendly standard processes for the institute or organization involved.

4) Managed: the detailed process measures as well as the quality of products can be collected to make the process easy and the product involved can be controlled and understood.

5) Optimizing: the regular and continued process enhancement can be facilitated, particularly by feedback from the process involved, as well as from the piloting technologies and other innovative ideas.

Critically, CMM's originality was designed in order to offer these various benefits, such as offering certain road maps for enhancing the software development process of the institute or organization [10].

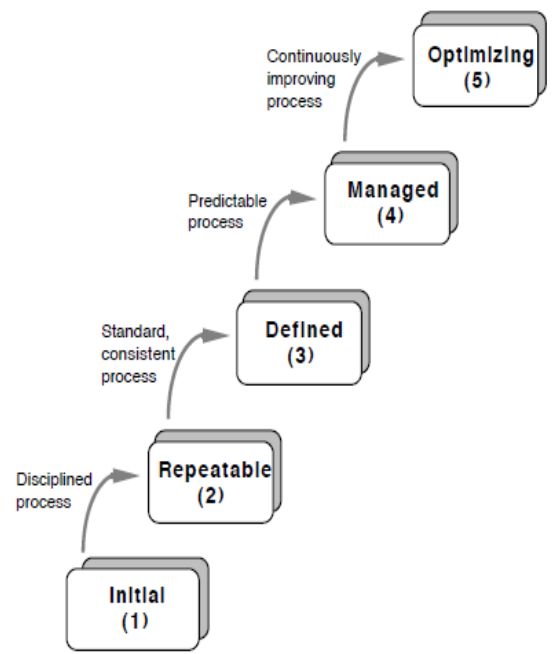

Figure. 3 Five Levels of CMM [10]

\section{Related work}

In spite of the adoption of E-Learning, which was demonstrated rapidly among most of those education institutions, one should ensure that there is an effectiveness and efficiency in the employment of such techniques for the organizational resources that may appear to be hard tasks. In literature there are many resources that handled such techniques with care [2] [4]. Corresponding to this point, one can figure out that many challenges appear simply because the many users involved cannot employ the convenient software and understanding the usage of such techniques [24].

What is actually required is to find out a process model what will help users get sufficient flexibility to guide the enhancement of the process of $\mathrm{m}$ Learning. The capability maturity model of CMM is a framework that fulfills all such requirements. It is easy to see the advantages offered by CMM in the educational sector as it is almost a tailor-made technique assess the implementation of a new versatile learning platform with wide reaching benefit. In fact the application of CMM to assess the educational process is not entirely a new concept, as shown in [25].

Checking E-Learning Maturity Model (EMM), one can refer to the argument of Marshall \& Mitchell [26][27][28] that focused on the enhancement of such a process of the involved software and, additionally, the ability of the model determination SPICE ISO/IEC [24]. However, one can still notice that SPICE is considered a reply of ISO, especially on the CMM of SEI', whereas it could employ mainly those 5 levels of the maturity, added to extra standard zero; indeed, for such process that could not be performed, or even might be performed on an incomplete basis.

Truly, the best practices and benchmarks for the process of E-Learning were examined and employed to compile a certain set of the targeted practices that might be suitable in 5 areas. The levels of maturity, unlike CMM, could be employed mainly in evaluating each of the practices, not only for the entire organization. However, one may still notice that the given results can be a framework, obviously for evaluating the maturity of E-Learning that could be applied to the systems of E-Learning of many universities in New Zealand [27][28].

It appears that the basic objectives of EMM regarding the educational process may appear like those of CMM, whereas its revealed domain appears different. This is not convenient to our aim. There are certain practices that could be applied, such as Neuhauser [29] offered OCDMM (Online Course Design Maturity model that as well may be considered as E-Learning's maturity model, focusing on CMM. Such a model can describe various states of E-learning technologies' adoption. However, mainly the difference between those levels can be figured out in the degree to which the technology of E-Learning can be employed successfully.

Consequently, despite the fact that both maturity models correspond to education, it has to be accepted that both are entirely different in actuality and cannot be compared to each other that they are different in full, and we cannot compare them [25]. 
However, the CMM model has been successfully modified and adapted to assess maturity in varied software application domains like the usability of open source software [30] and software product line engineering maturity [31]. This proves that with appropriate modifications, the CMM model can be adapted to assess the maturity of m-Learning within educational institutions as well, which is the primary goal of this paper.

A review of the work has shown that CMM has not been applied critically in the domain of teaching, except for the above-mentioned work [25]. Other educational maturity models appear to either rely on developing professionalism in the context of industry or on the process of E-Learning, considered a special domain. Neither of such approaches could be applicable on the m-Learning generally, yet may later inspire the best analogous practices. Indeed, from conducting such analysis one can see that mLearning modules, coupled with certain structured assessments, have their potential simply in order to improve the educational experiences.

\section{Proposed m-Learning Maturity Model}

From such critical point, the main target therefore is to figure out a proposed model for the m-Learning maturity model. The authors have published a research paper [32] [33] as an initial maturity model for m-Learning. In this paper a new level were add to there are six basic stages in the proposed model as follows:

\section{Level Zero:}

Based on the SPICE ISO/IEC [24] level 0 in this case it is recognized as a limited mobile presence. In this stage, universities and the institutions do not consider mobile devices to be important in the provision of their services and products. As a result, there are no systems or procedures to encourage the students to utilize the mobile devices; therefore, they do not invest in developing mobile learning systems.

\section{First Level:}

This level is known as the preliminary stage. It is a reactive and experimental stage that, once initiated by the learning institution, recognizes the need to improve the provision of information to students through mobile devices. The institutions react to the external pressures and needs for flexibility and convenience by students.

In this level, the institution has the pilot program for implementation but there is a lack of a vision to guide the implementation. The institutions develop measures to facilitate the implementation of the prototypes. This is done experimentally but is hampered for a number of reasons. For instance, the mobile device coverage might be limited or students might not understand the value of the mobile learning environment.

Another limitation in the implementation of the prototype might be the fact that the learning institution might not have the ability to facilitate effective implementation. In the preliminary stage, most of the universities and institutions do not have clear mobile learning policies and defined objectives to guide mobile learning; these factors might limit the implementations and the usage of the systems.

\section{Second Level:}

The establishment stage, is based on the recognition of the opportunity provided by mobile devices in the education system. This resulted in the investment of m-Learning technologies to realize the opportunities provided. In this stage, learning institutions formulate clear objectives to guide mLearning implementation. However, those Institutions do not have m-Learning mechanisms to evaluate their systems. This brings the need for improvements on the existing and implemented pilot prototypes. Programmers develop systems to facilitate the use of mobile learning in education such as the Android App Education and iOS App Education [3].

\section{Third Level:}

In the defined stage, the model of mobile learning environment has been developed to measure the quality of mobile learning systems. The focus on learning mobile systems by institutions features to offer the most mobile platforms. In the defined stage, the mobile device is considered as a critical tool in the interaction between students or among students, instructors and administrative staff. Learning institutions must link their mobile learning strategies with core and technical visions, and they must invest heavily in this type of systems to achieve success. This can be done by establishing clear guidelines to reach the desired level of success.

\section{Fourth Level:}

The structured stage; in this level, m-Learning is characterized by optimization and innovation. The optimization results in a rich, dynamic, and flawless experience for students and tutors in the use of the system. To solidify their systems, institutions borrow and integrate the best practices from other institutions. Universities develop and measure to ensure a real time student engagement and context awareness. Also, they develop systems to be used in different mobile devices such as tablets and mobile phones. The use of mobile device applications allows students to provide feedback, give comments, and 
share information. As a result, institutions refine and improve procedures and policies to control any changes experienced in mobile changes.

Fifth Level:

Finally, the continuous improvement stage; in this stage mobile offering has already been accepted as the best approach to provide knowledge and exchange of information between students and instructors. In this stage, institutions are constantly evaluating themselves to ensure continuous improvement and optimization. This helps identify any changes that occur that might limit or change the manner in which mobile learning is used.

\section{Conclusion}

Getting involved with the highest technical tools may be confusing, especially when they are used in the education process. Checking the differences between m-Learning and E-Learning, one can understand that the first is most recently developed, especially after the high revolution in creating mobile devices, which can be used widely by either students or others. In turn, m-Learning can make the connection easier, since it does not need to be limited into certain place, such as computers.

This research contributes toward an initial maturity evaluation of mobile learning. However, the maturity model illustrated helps understand the realization of an m-Learning model. It provides an assessment of the provision of education through mobile learning and the capabilities of the method. It also provides a literature review on m-Learning, helping show its effectiveness and challenges.

The value gained from such a paper is demonstrating the possibility of adapting CMM in order to present such a valuable road map especially to support institutional and individual efforts that might enhance the process of organization that could be collaborated with m-Learning. If we encounter such questions, whereas it is a valid process, we can simply answer that while it is obvious that such models appear incomplete, they can, however, present many benefits.

In short, one can add that such mentioned frameworks could not provide a complete of such list of the necessary key processes, particularly for enhancing the process of m-Learning, just such indicative set of those possible results, in order to define each of those levels that may be possible in the maturity model. This is not an exhaustive study, but it still contributes many possible results. Clearly, the following step in developing such a model could be figured out in identifying the key activities that have led to the improvements in earning m-Learning. We hope in the future to conduct a comprehensive study that will involve empirically testing the maturity model illustrated and help to develop a statistical model on the same

\section{Acknowledgment}

The first author would like to thank the Ministry of Higher Education (MOHE) in Saudi Arabia for his scholarship.

\section{References}

[1] A. Kukulska-Hulme, J. Pettit, L. Bradley, A. A. Carvalho, A. Herrington, D. M. Kennedy, and A. Walker, "Mature students using mobile devices in life and learning," International Journal of Mobile and Blended Learning, vol. 3, no. 1, pp. 18-52, 2011.

[2] G. Engel, R. Palloff, and K. Pratt, "Using mobile technology to empower student learning," in 27th Annual Conf. on Distance Teaching \& Learning, pp. $1-4,2011$.

[3] T. Elias, "Universal instructional design principles for mobile learning," International Review of Research in Open and Distance Learning, vol. 12, no. 2, pp. 143156, 2011.

[4] D. Frohberg, C. Göth, and G. Schwabe, "Mobile learning projects - a critical analysis of the state of the art," Journal of Computer Assisted Learning, vol. 25, no. 4, pp. 307-331, 2009.

[5] Y. Huang, W. Hwang, and K. Chang, "Guest editorial-innovations in designing mobile learning applications," Educational Technology \& Society, vol. 13, pp. 1-2, 2010.

[6] J. Wishart, and D. Green, (2010), "Identifying emerging issues in mobile learning in higher and further education" A report to JISC [Online], Available http://www.jiscdigitalmedia.ac.uk/blog/entry/resource s-for-mobile-learning [Feb 21, 2013]

[7] A. T. Korucu and A. Alkan, "Differences between mLearning (mobile learning) and e-learning, basic terminology and usage of m-Learning in education," Procedia - Social and Behavioral Sciences, vol. 15, pp. 1925-1930, Jan. 2011.

[8] F. Ozdamli and N. Cavus, "Basic elements and characteristics of mobile learning," Procedia - Social and Behavioral Sciences, vol. 28, pp. 937-942, Jan. 2011.

[9] A. Ali, A. Ouda, and L.F. Capretz, "A conceptual framework for measuring the quality aspect of mobile learning", Bulletin of the IEEE Technical Committee on Learning Technologies, IEEE Press, vol. 14, no. 4, pp. 31-34, 2012.

[10] M. Pauik, B. Curtis, and C. Weber, "The capability maturity model for software," pp. 1-26, 1997.

[11] J. Paul and R. Seth, "Japan-India diplomacy and relationship marketing", International Marketing text and Cases, J. Paul, Ed., 2nd ed., New Delhi: Tata McGraw-Hill Education, 2012, pp. 178-180.

[12] RFE/RL, (2012), "Report says 75 percent of world's population have mobile phones", July 17 2012, 
[Online],

Available

From

http://www.rferl.org/content/report-says-75-percentof-worlds-population-have-mobile-

phones/24648234.html.

[13] Q. Li, R. W. H. Lau, T. K. Shih, and F. W. B. Li, "Technology supports for distributed and collaborative learning over the internet," in ACM Transactions on Internet Technology, vol. 8, no. 2, pp. $1-24,2008$

[14] S. I. Wains and W. Mahmood, "Integrating mlearning with e-learning," in Proc. of the 9th ACM SIGITE Conferenceon Information Technology Education, Ohio, 2008

[15] C. P. Schofield, T. West, and E. Taylor, (2011), Going mobile in executive education: how mobile technologies are changing the executive landscape [Online] Available: https://uniconexed.org/2011/research/UNICONGoing_Mobile_In_Executive_Education-SchofieldTaylor-West-Nov-2011.pdf.

[16] R. Earnshaw, "From e-Learning to m-Learning - the use of mixed eeality games as a new educational paradigm," International Journal of Interactive Mobile Technologies iJIM, vol. 5, no. 2, pp. 17-25, 2011.

[17] J. Lam, J. Yau, and S. Cheung, "A review of mobile learning in the mobile age," Hybrid Learning, vol. 2, no. 2005, pp. 306-315, 2010.

[18] N. C. Ozuorcun and F. Tabak, "Is m-Learning versus e-learning or are they supporting each other?," Procedia - Social and Behavioral Sciences, vol. 46, pp. 299-305, Jan. 2012.

[19] E. Teall, M. Wang, and V. Callaghan, "A synthesis of current mobile learning guidelines and frameworks m-Learning design guidelines," In Proc. of World Conf. on E-Learning in Corporate, Govt., Healthcare, and Higher Education 2011, pp. 443-451, 2011.

[20] S. Bidin, A. A. Ziden, "Adoption and application of mobile learning in education industry", in $6^{\text {th }}$ International Conference on University Learning and Teaching, Social and ehavioural Sciences vol. 90, pp. 720-729, 2013.

[21] L. Naismith and D. Corlett, "Reflections on success: a retrospective of the mLearn conference eeries 20022005", mLearn 2006 - Across Generations and Cultures, Banff, Canada, [Online], Available From http://hal.archivesouvertes.fr/docs/00/19/73/66/PDF/Naismith-Corlett2006.pdf.

[22] M. Prensky, "How to teach with technology: Keeping both teachers and students comfortable in an era of exponential change.", Emerging Technologies for Learning, 2, 40-46. 2007 [Online], Available From http://partners.becta.org.uk/page documents/research/ emerging_technologies07_chapter4.pdf

[23] O. Smørdal and J. Gregory, "KNOWMOBILE mobile opportunities for medical students.", inn A. Kukulska-Hulme \& J. Traxler (Eds.), Mobile learning: A handbook for educators and trainers (pp. 99-105). London: Routledge, 2005
[24] ISO IEC, “ISO/IEC TR 15504:1998 Information technology - software process assessment Part 3:performing an assessment," ISO/IEC, 1998.

[25] C. Lutteroth and A. Luxton-Reilly, "A maturity model for computing education," in Proc. ninth Australasian Conf. on Computing education, vol. 66, pp. 107-114, 2007.

[26] S. Marshall and G. Mitchell, "An e-learning maturity model," in 19th Annual Conf. of the Australian Society for Computers in Learning in Tertiary Education, 2002

[27] S. Marshall and G. Mitchell, "Potential indicators of e-learning process capability," Proc. of EDUCAUSE in Australasia, no. Cmm, pp. 1-8, 2003.

[28] S. Marshall and G. Mitchell, "Applying SPICE to elearning: an e-learning maturity model?," In Proc. of the Sixth Australasian Conf. on Computing Education, Australian Computer Society, Inc.,, vol. 30, pp. 185-191., 2004.

[29] C. Neuhauser "A maturity model: does it provide a path for online course design," The Journal of Interactive Online Learning, vol. 3, no. 1, pp. 1-17, 2004.

[30] A. Raza, L.F. Capretz, and F. Ahmed, "An open source usability maturity model (OSUMM)", Computers in Human Behavior, Elsevier, vol. 28, Issue 4, 2012, pp. 1109-1121.

[31] F. Ahmed and L.F. Capretz, "An organizational maturity model of software product line engineering", Software Ouality Journal, Springer, vol. 18, Issue 2, 2010, pp. 195-225.

[32] M. Alrasheedi and L.F Capretz, "Applying CMM towards an m-learning context" International Conference on Information Society (i-Society), 2013, pp.146-151.

[33] M. Alrasheedi and L.F Capretz, "An M-Learning Maturity Model for the Educational Sector" The Sixth Conference of MIT's Learning International Networks Consortium (LINC), MIT, Cambridge, Massachusetts, USA, June 16th - 19th, 2013. availble online: http://ir.lib.uwo.ca/cgi/viewcontent.cgi?article $=1065$ \&context=electricalpub 